\title{
Kumaraswamy Inverse Lindley Distribution with Stress-Strength Reliability
}

\author{
Saeed E. HEMEDA ${ }^{\mathfrak{0}}$, Sukanta PRAMANIK*,b®, Sudhansu S. MAITI ${ }^{\complement}$ \\ a Obour High Institute for Management \& Informatics, CAIRO, EGYPT \\ ${ }^{b, *}$ Department of Statistics, Siliguri College, North Bengal University, INDIA \\ ${ }^{c}$ Department of Statistics, Visva-Bharati University, 731235, SANTINIKETAN, INDIA
}

\section{ARTICLE \\ INFO \\ Received: 18.05.2020 \\ Accepted: 13.10 .2020 \\ Keywords: \\ Kumaraswamy inverse \\ Lindley; Maximum \\ likelihood; Moments; \\ Quantile function; \\ Stress-Strength \\ reliability; Simulation \\ "Corresponding \\ Authors \\ e-mail: \\ skantapramanik@gmai \\ 1.com}

\begin{abstract}
A new generalization of inverse Lindley distribution, called Kumaraswamy inverse Lindley is presented in this study. Some mathematical expressions are determined for the proposed distribution. Significant statistical measures are deduced including quantiles, generating functions, ordinary and incomplete moments, entropies, mean deviations, and order statistics. Some other properties like median, mean, variance, coefficient of variation, coefficients of skewness, and kurtosis are characterized. Moreover, stress-strength reliability is defined. A simulation study of the Kumaraswamy inverse distribution is introduced using maximum likelihood estimation and the performances of their estimates are compared through biases and mean square errors. The applicability and importance of the new distribution are illustrated through two real data sets.
\end{abstract}

https://dx.doi.org/10.30855/gmbd.2020.03.09

\section{Kumaraswamy Gerilme-Dayanım Güvenilirliği ile Ters Lindley Dağılımı}

\section{MAKALE \\ BíLGísi \\ Alınma: 18.05.2020 \\ Kabul: 13.10.2020 \\ Anahtar Kelimeler: \\ Kumaraswamy ters \\ Lindley, Maksimum \\ olasılık, Anlar; Nicelik \\ işlevi, Stress-Strength \\ güvenilirliğ $i$, \\ Simülasyon

\author{
Sorumlu yazar \\ e-posta: \\ skantapramanik@gmai \\ 1.com
}

\section{ÖZ}

$\mathrm{Bu}$ çalışmada, Kumaraswamy ters Lindley adı verilen ters Lindley dağılımının yeni bir genellemesi sunulmuştur. Önerilen dağılım için bazı matematiksel ifadeler belirlenmiştir. Nicelikler, üreten fonksiyonlar, siradan ve eksik anlar, entropiler, ortalama sapmalar ve sira istatistikleri dahil olmak üzere önemli istatistiksel ölçümler çıkarılmıştır. Medyan, ortalama, varyans, varyasyon katsayısı, çarpıklık katsayıları ve basıklık gibi diğer bazı özellikler karakterize edilmiştir. Dahası, gerilme mukavemeti güvenilirliği tanımlanmıştır. Kumaraswamy ters dağılımının bir simülasyon çalışması, maksimum olasılık tahmini kullanılarak tanıtılmış ve tahminlerinin performansları, önyargılar ve ortalama kare hataları ile karşılaştırılmıştır. Yeni dağıtımın uygulanabilirliği ve önemi iki gerçek veri seti ile gösterilmektedir.

https://dx.doi.org/10.30855/gmbd.2020.03.09

Bu makaleye atıf yapmak için: S.E. Hemedaa, S. Pramanik, S.S. Maitic, "Shortest Path Approach in Pedestrian Transfers Application in Unity," Gazi Journal of Engineering Sciences, vol. 6, no. 3, pp. 255-264, December, 2020, doi: https://dx.doi.org/10.30855/gmbd.2020.03.09. 


\section{INTRODUCTION}

The inverse Lindley (IL) distribution is an important probability distribution in analyzing lifetime data with some monotone failure rates. It is used in enormous applications, particularly in survival analysis, engineering and agriculture. It is a popular model used in economics. Recently, an extension of inverse Lindley distribution with two parameters is introduced by Merovci and Sharma [1]. Threeparameter inverse Lindley distributions with the application are proposed by Alkarni [2]. Also, Sharma et al [3] has determined the properties of inverse Lindley distribution with stress strength reliability analysis. Another extension of inverse Lindley distribution, called extended inverse Lindley (EIL) is investigated by Sharma and Khandelwal [4].

The inverse Lindley (IL) distribution is proposed by the following probability density function (PDF) and cumulative distribution function (CDF), respectively

$$
\begin{aligned}
& f(x ; \theta)=\frac{\theta^{2}}{1+\theta}\left(\frac{1+x}{x^{3}}\right) e^{-\frac{\theta}{x}} ; x>0, \theta>0, \\
& G(x ; \theta)=\left(1+\frac{\theta}{(1+\theta) x}\right) e^{\frac{-\theta}{x}} .
\end{aligned}
$$

In our work, we have shown in detail a new generalization of inverse Lindley distribution using the Kumaraswamy generator. The Kumaraswamy $\mathrm{Ku})$ distribution with two parameters is proposed by Kumaraswamy [5] with PDF and CDF as follows $\mathrm{g}(x ; \alpha, \beta)=\alpha \beta x^{\alpha-1}\left(1-x^{\alpha}\right)^{\beta-1} ; x \in(0,1), \alpha, \beta>0$.

$G(x ; \alpha, \beta)=1-\left(1-x^{\alpha}\right)^{\beta}$,

where $\alpha>0$ and $\beta>0$ are shape parameters. For any baseline cumulative distribution function $G(x)$, Nadarajah et al. [6] defined Kumaraswamy generating family of distributions as follows

$$
\begin{aligned}
& f_{k u-G}(x)=\alpha \beta g(x)(G(x))^{\alpha-1}\left(1-(G(x))^{\alpha}\right)^{\beta-1}, \\
& F_{k u-G}(x)=1-\left(1-(G(x))^{\alpha}\right)^{\beta} .
\end{aligned}
$$

Cordeiro et al. [4] studied Kumaraswamy Weibull distribution, Paranaiba et al. [7] discussed Kumaraswamy Burr distribution, and Gomes et al. [8] presented Kumaraswamy generalized Rayleigh distribution. Recently, Corderio et al. [9, 10] introduced the Kumaraswamy Exponential-Weibull, and Al-Babtain et al. [11] determined Kumaraswamytransmuted exponentiated modified Weibull distribution, etc.

\section{THE PROPOSED MODEL}

This section provides the formation of Kumaraswamy inverse Lindley (KuIL) distribution mathematically. The $\mathrm{CDF}$, reliability, hazard rate, cumulative hazard rate function are obtained and studied the behavior and shape of the new model.

By substituting (1) and (2) into (3), the KuIL PDF is given by

$$
f_{\text {KulL }}(x)=\frac{\alpha \beta \theta^{2}}{1+\theta}\left(\frac{1+x}{x^{3}}\right)\left(1+\frac{\theta}{(1+\theta) x}\right)^{\alpha-1}\left(1-\left(1+\frac{\theta}{(1+\theta) x}\right)^{\alpha} e^{\frac{-\theta \alpha}{x}}\right)^{\beta-1} e^{\frac{-\theta \alpha}{x}} .
$$

The CDF is

$$
F_{\text {KulL }}(x)=1-\left(1-\left(1+\frac{\theta}{(1+\theta) x}\right)^{\alpha} e^{\frac{-\theta \alpha}{x}}\right)^{\beta} \text {. }
$$

The reliability $\mathrm{S}_{\text {KuIL }}(\mathrm{x})$ and hazard rate $\mathrm{h}_{\text {KuIL }}(\mathrm{x})$ functions of KuIL are given as follows

$$
\begin{aligned}
& S_{\text {KulL }}(x)=\left(1-\left(1+\frac{\theta}{(1+\theta) x}\right)^{\alpha} e^{\frac{-\theta \alpha}{x}}\right)^{\beta}, \\
& h_{\text {KulL }}(x)=\frac{\alpha \beta \theta^{2}(1+x)\left(1+\frac{\theta}{(1+\theta) x}\right)^{\alpha-1} e^{\frac{-\theta \alpha}{x}}}{(1+\theta) x^{3}\left(1-\left(1+\frac{\theta}{(1+\theta) x}\right)^{\alpha} e^{\frac{-\theta \alpha}{x}}\right.} .
\end{aligned}
$$

Additionally, the cumulative hazard rate $\mathrm{H}_{\mathrm{KuIL}}(\mathrm{x})$ function is given by

$H_{K u I L}(x)=-\log S(x)=-\beta \log \left\{1-\left(1+\frac{\theta}{(1+\theta) x}\right)^{\alpha} e^{\frac{-\theta \alpha}{x}}\right\}$.

It is noticed that when $\alpha=\beta=1$, then the KuIL distribution reduces to IL distribution and when $\beta=1$, then the KuIL distribution reduces to two parameter IL distribution.

The KuIL function can exhibit different behavior depending on the values of the parameters as shown in Figure 1.

Plots of PDF and hazard rate function of KuIL distribution are shown in Figures 1 and 2 for some values of parameters. Figure $2 \mathrm{a}$ shows that the $h_{K u I L}(x)$ has monotone decreasing and down bathtub shaped failure rate. 


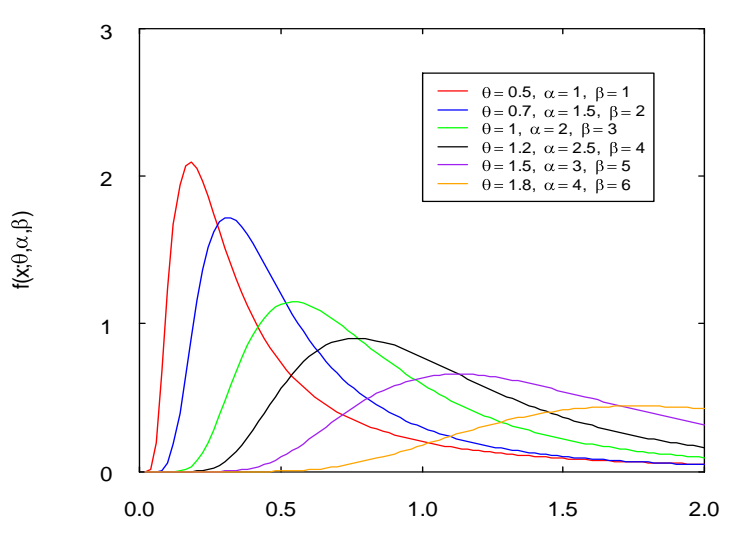

Figure 1: The PDFs of KuIL distribution.

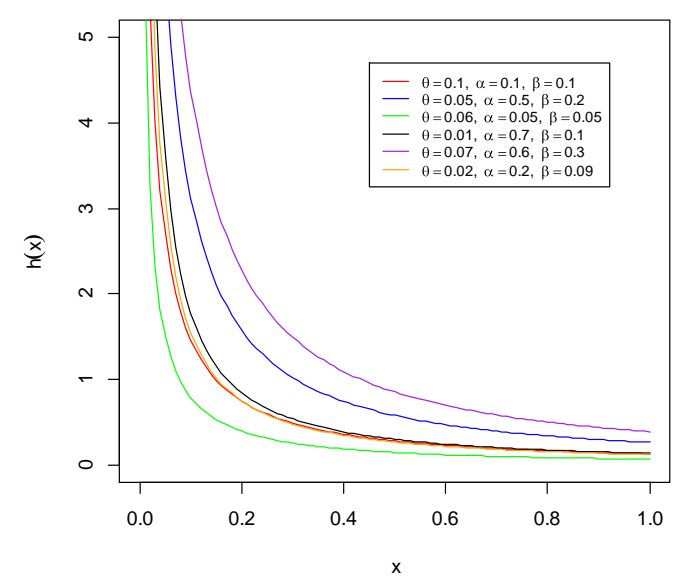

(a)

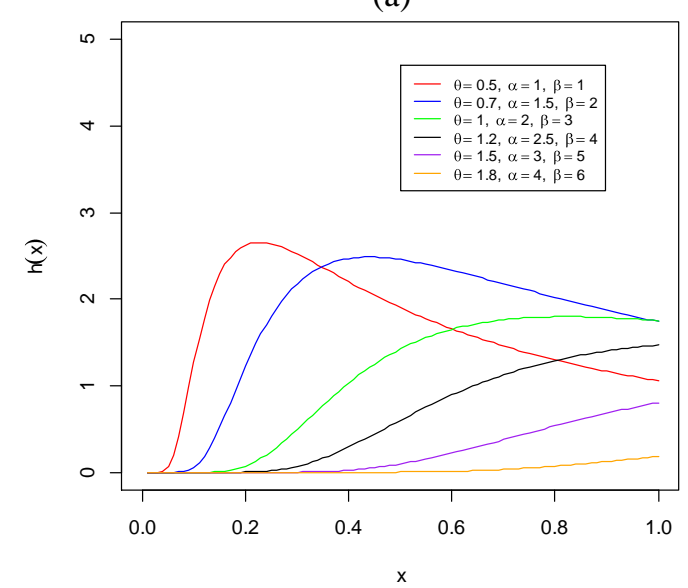

(b)

Figure 2. a)The $h_{\text {KuIL }}(x)$ of KuIL distribution, b) The $h_{\text {KuIL }}(x)$ of KuIL distribution.

\section{USEFUL MATHEMATICAL FORMULAS}

Some useful mathematical formulas of KuIL are computed in this section. By applying the binomial theorem and substituting in the PDF (5)

$$
\begin{aligned}
& {\left[1-\left(1+\frac{\theta}{(1+\theta) x}\right)^{\alpha} e^{\frac{-\theta \alpha}{x}}\right]^{\beta-1}=\sum_{j=0}^{\infty}(-1)^{j}\left(\begin{array}{l}
\beta-1 \\
j
\end{array}\right)\left(1+\frac{\theta}{(1+\theta) x}\right)^{\alpha j} e^{\frac{-\theta \alpha j}{x}}} \\
& f_{\text {KuLL }}(x)=\sum_{j=0}^{\infty}(-1)^{j}\left(\begin{array}{l}
\beta-1 \\
j
\end{array}\right) \frac{\alpha \beta \theta^{2}}{1+\theta}\left(\frac{1+x}{x^{3}}\right)\left(1+\frac{\theta}{(1+\theta) x}\right)^{\alpha(j+1)-1} e^{\frac{-\theta \alpha j}{x}} .
\end{aligned}
$$

Also, using the rule of exponential function as a power series:

$$
\left(1+\frac{\theta}{(1+\theta) x}\right)^{\alpha(j+1)-1}=\sum_{k=0}^{\infty}\left(\begin{array}{l}
\alpha(j+1)-1 \\
k
\end{array}\right) \frac{\theta^{k}}{(1+\theta)^{k} x^{k}}
$$

Therefore, the PDF of KuIL can be written in the following expression:

$$
\begin{aligned}
& f_{\text {KulL }}(x)=\sum_{j=0}^{\infty} \sum_{k=0}^{\infty} \alpha \beta(-1)^{j}\left(\begin{array}{l}
\beta-1 \\
j
\end{array}\right)\left(\begin{array}{l}
\alpha(j+1)-1 \\
k
\end{array}\right)\left(\frac{\theta^{k+2}}{(1+\theta)^{k+1}}\right)\left(\frac{1+x}{x^{k+3}}\right) e^{\frac{-\theta \alpha(j+1)}{x}} . \\
& f_{\text {KuLL }}(x)=\sum_{j, k=0}^{\infty} \Xi_{\mathrm{j}, \mathrm{k}}\left[\left(\frac{1}{x}\right)^{k+3} e^{\frac{-\theta \alpha(j+1)}{x}}+\left(\frac{1}{x}\right)^{k+2} e^{\frac{-\theta \alpha(j+1)}{x}}\right],
\end{aligned}
$$

where, $\Xi_{\mathrm{j}, \mathrm{k}}=\alpha \beta(-1)^{j}\left(\begin{array}{l}\beta-1 \\ j\end{array}\right)\left(\begin{array}{l}\alpha(j+1)-1 \\ k\end{array}\right)\left(\frac{\theta^{k+2}}{(1+\theta)^{k+1}}\right)$

The corresponding CDF will be:

$$
\begin{aligned}
& F_{\text {KulL }}(x)=1-\sum_{m, p=0}^{\infty} \Xi_{m, p}\left(\frac{1}{x}\right)^{p} e^{\frac{-\theta \alpha m}{x}}, \\
& \text { where, } \Xi_{m, p}=\sum_{m, p=0}^{\infty}(-1)^{m}\left(\begin{array}{l}
\beta \\
m
\end{array}\right)\left(\begin{array}{l}
\alpha m \\
p
\end{array}\right)\left(\frac{\theta^{p}}{(1+\theta)^{p}}\right) .
\end{aligned}
$$

Additionally, the reliability function is defined in the following series expansion:

$$
S_{\text {KuLL }}(x)=\sum_{m, p=0}^{\infty} \Xi_{m, p}\left(\frac{1}{x}\right)^{p} e^{\frac{-\theta \alpha m}{x}} \text {. }
$$

\section{SIGNIFICANT STATISTICAL MEASURES}

Some significant statistical properties of KuIL distribution, specifically quantile function, moments, moment generating function, mean residual life, Rényi and q-entropies and order statistics will be provided.

\subsection{Quantile function and Median}

The quantile function of the KuIL distribution $q(u)=F^{-1}(u)$ is computed by inverting $\mathrm{CDF}(6)$ as follows 
$\ln \left(1+\frac{\theta}{(1+\theta) x_{q}}\right)-\frac{\theta}{x_{q}}=\frac{1}{\alpha} \ln \left(1-(1-u)^{\frac{1}{\beta}}\right)$

where, $x_{q}=q(u)$, and $u$ has the uniform distribution. By solving equation (11) numerically for $x_{q}$, the quantile function is to be calculated.

Hence, the median $x_{M}$ of the distribution is derived by substituting $u=0.5$ in (11) as follows

$\ln \left(1+\frac{\theta}{(1+\theta) x_{M}}\right)-\frac{\theta}{x_{M}}=\frac{1}{\alpha} \ln \left(1-(0.5)^{\frac{1}{\beta}}\right)$,

where $x_{M}=q(0.5)$.

\subsection{Moments, Skewness and Kurtosis}

Moments play an important role in most statistical analyses. It is mostly used to study the characteristics of any probability distribution such as the measures of central tendency and the measures of dispersion.

The $\boldsymbol{n}^{\text {th }}$ moment for KuIL distribution about zero will be obtained here. The $\boldsymbol{n}^{\text {th }}$ moment of random variable $X$ can be determined from (8) as follows

$$
\begin{aligned}
& E\left(X^{n}\right)=\int_{0}^{\infty} x^{n} f_{\text {KuLL }}(x) d x, \\
& E\left(X^{n}\right)=\sum_{j, k=0}^{\infty} \Xi_{\mathrm{j}, k}\left[\frac{\Gamma(k-n+2)}{(\theta \alpha(j+1))^{k-n+2}}+\frac{\Gamma(k-n+1)}{(\theta \alpha(j+1))^{k-n+1}}\right] .
\end{aligned}
$$

Specifically, the mean $\mathrm{E}(\mathrm{X})$ and variance $\mathrm{V}(\mathrm{X})$ of KuIL distribution are computed as follows

$$
\begin{aligned}
E(X)= & \sum_{\mathrm{j}, k=0}^{\infty} \Xi_{\mathrm{j}, k} \\
E\left(X^{2}\right)= & \sum_{j, k=0}^{\infty} \Xi_{\mathrm{j}, k}\left[\frac{\Gamma(k+1)}{(\theta \alpha(j+1))^{k+1}}+\frac{\Gamma(k)}{(\theta \alpha(j+1))^{k}}\right] \\
V(x)= & \sum_{j, k=0}^{\infty} \Xi_{j, k}\left[\frac{\Gamma(k+1))^{k}}{(\theta \alpha-1)} \frac{\Gamma(k)}{[\theta \alpha(j+1))^{k-1}}+\frac{\Gamma(k-1)}{[\theta \alpha(j+1)]^{k-1}}\right] \\
& -\left[\sum_{j, k=0}^{\infty} \Xi_{j, k}\left[\frac{\Gamma(k+1)}{[\theta \alpha(j+1)]^{k+1}}+\frac{\Gamma(k)}{[\theta \alpha(j+1)]^{k}}\right]\right]^{2}
\end{aligned}
$$

where, $\Xi_{j, k}=\alpha \beta(-1)^{j+1}\left(\begin{array}{l}\beta-1 \\ j\end{array}\right)\left(\begin{array}{l}\alpha(j+1)-1 \\ k\end{array}\right)\left(\frac{\theta^{k+2}}{(1+\theta)^{k+1}}\right)$

By Using (13), the skewness(Skew) and kurtosis (Kur) coefficients of KuIL distribution can be calculated using the following relations

Skew $=\frac{\mu_{3}^{\prime}-3 \mu_{2}^{\prime} \mu_{1}^{\prime}+2 \mu_{1}^{\prime 3}}{\left(\mu_{2}^{\prime}-\mu_{1}^{\prime 2}\right)^{3 / 2}}$, Kur $=\frac{\mu_{4}^{\prime}-4 \mu_{3}^{\prime} \mu_{1}^{\prime}+6 \mu_{2}^{\prime} \mu_{1}^{\prime 2}-3 \mu_{1}^{\prime 4}}{\left(\mu_{2}^{\prime}-\mu_{1}^{\prime 2}\right)^{2}}$.

where $\mu_{1}, \mu_{2}, \mu_{3}$ and $\mu_{4}$ are the first four moments about origin.

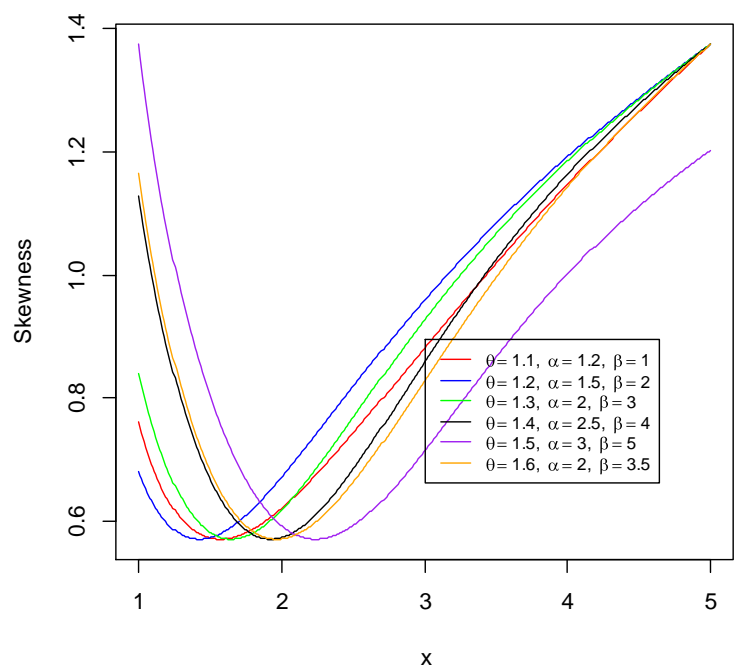

(a)

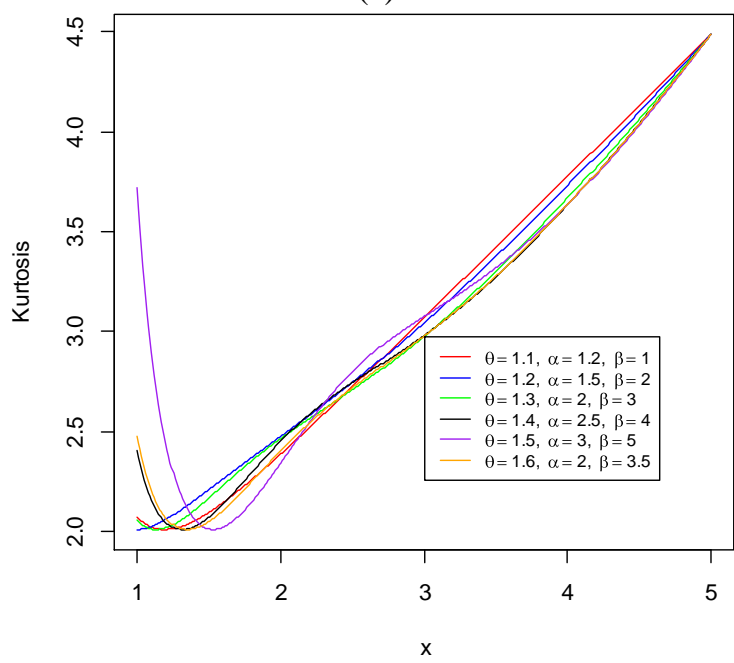

(b)

Figure 3. a) Skewness of KuIL distribution, b) Kurtosis of KuIL distribution.

\subsection{Moment generating and mean residual life functions}

The moment generating function $M_{g}(t)$ of KuIL distribution can be determined as follows.

By the definition ${ }_{M_{g}}(t)=\sum_{n=0}^{\infty} \frac{t^{n} \mu_{n}^{\prime}}{n !}$ and using (13), the moment generating function is obtained as

$M_{g}(t)=\sum_{\mathrm{j}, k, n=0}^{\infty} \frac{\Xi_{\mathrm{j}, k} t^{n}}{n !}\left[\frac{\Gamma(k-n+2)}{(\theta \alpha(j+1))^{k-n+2}}+\frac{\Gamma(k-n+1)}{(\theta \alpha(j+1))^{k-n+1}}\right]$.

Given that a component survives up to time $t \geq$ 0 , the residual life is the period beyond $t$ until the time of failure and defined by the conditional random variable $[(X-t) \mid X>t]$. In reliability, it is well known that the mean residual life function and ratio of two consecutive moments of residual life determine 
the distribution uniquely [12]. The mean residual life of KuIL distribution $[m(t)]$ is defined by

$m(t)=\frac{1}{1-F(t)} \int_{t}^{\infty} x f(x) d x-t$.

Hence, by using PDF (8) and reliability function (10) of KuIL distribution, the mean residual life time is derived as follows

$$
m(t)=\frac{\sum_{j, k=0}^{\infty} \Xi_{\mathrm{j}, \mathrm{k}}\left[\int_{t}^{\infty}\left(\frac{1}{x}\right)^{k+2} e^{\frac{-\theta \alpha(j+1)}{x}} d x+\int_{t}^{\infty}\left(\frac{1}{x}\right)^{k+1} e^{\frac{-\theta \alpha(j+1)}{x}} d x\right]}{\sum_{m, p=0}^{\infty} \Xi_{m, p} t^{-p} e^{\frac{-\theta \alpha m}{x}}}-t .
$$

$$
\text { Replacing } \Gamma(v, t)=\int_{t}^{\infty} x^{v-1} e^{-v} d x
$$

the

incomplete gamma function, we have

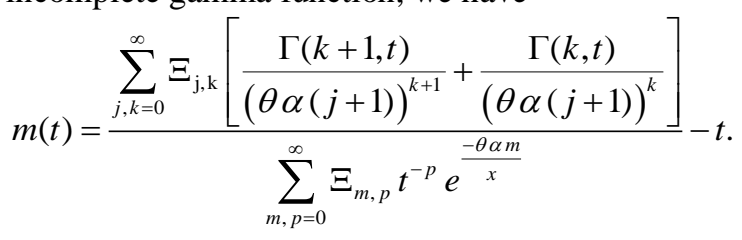

\subsection{Rényi and d-Entropies}

We study Rényi [13] and $d$ entropies in this section. The Rényi entropy $[\operatorname{Re} n(\zeta)]$ of a random variable $X$ is defined by

$\operatorname{Re} n(\zeta)=\frac{1}{1-\zeta} \log \left[\int_{0}^{\infty} f^{\zeta}(x) d x\right]$,

where, $\zeta>0$ and $\zeta \neq 1$. Substituting (5) into last equation and after some mathematical abbreviations, we get

$\operatorname{Re} n_{\text {KulL }}(\zeta)=\frac{1}{1-\zeta} \log \left[\sum_{s, \omega, v=0}^{\infty} \Lambda_{s, \omega, v} \frac{\Gamma(\omega+3 \zeta-v-1)}{(\theta \alpha(s+\zeta))^{\omega+3 \zeta-v-1}}\right]$,

where,

$\Lambda_{s, \omega, v}=\sum_{s, \omega, v=0}^{\infty}(-1)^{s}\left(\begin{array}{l}\zeta \\ v\end{array}\right)\left(\begin{array}{l}\zeta(\beta-1) \\ s\end{array}\right)\left(\begin{array}{l}\alpha s+\zeta(\alpha-1) \\ \omega\end{array}\right) \frac{\alpha^{\zeta} \beta^{\zeta} \theta^{\omega+2 \zeta}}{(1+\theta)^{\omega+\zeta}}$

The d-entropy $[\mathrm{I}(\mathrm{d})]$ is determined by the following relation

$I(d)=\frac{1}{d-1} \log \left[1-\int_{0}^{\infty} f^{d}(x) d x\right]$, where $d>0$ and $d \neq 1$

The d-entropy of KuILwill be

$I_{\text {KulL }}(d)=\frac{1}{d-1} \log \left[1-\sum_{s, \omega, v=0}^{\infty} \Upsilon_{s, \omega, v} \frac{\Gamma(\omega+3 d-v-1)}{(\theta \alpha(s+q))^{\omega+3 d-v-1}}\right]$ where,

$$
\Upsilon_{s, \omega, v}=(-1)^{s}\left(\begin{array}{l}
d \\
v
\end{array}\right)\left(\begin{array}{l}
d(\beta-1) \\
s
\end{array}\right)\left(\begin{array}{l}
\alpha s+d(\alpha-1) \\
\omega
\end{array}\right) \frac{\alpha^{d} \beta^{d} \theta^{\omega+2 d}}{(1+\theta)^{d+\omega}}
$$

\subsection{Stress-Strength Reliability}

The stress-strength reliability is defined as the probability that the system is strong enough to defeat the stress applied on it.

Let $\mathrm{X}$ and $\mathrm{Y}$ be independent stress and strength random variables, respectively follow KuIL distribution with parameters $\gamma_{1}=$ $\left(\theta_{1}, \alpha_{1}, \beta_{1}\right)$ and $\gamma_{2}=\left(\theta_{2}, \alpha_{2}, \beta_{2}\right)$, respectively. Then, the stress-strength reliability is defined as

$R_{\text {KuIL }}=P(Y<X)=\int_{0}^{\infty} f_{\text {KuIL }}\left(x ; \gamma_{1}\right) F_{\text {KuIL }}\left(x ; \gamma_{2}\right) d x$,

By substituting from (8) and (9), we obtain

$$
\begin{aligned}
& R_{\text {KulL }}=\int_{0}^{\infty}\left[\sum _ { j , k = 0 } ^ { \infty } \Xi _ { j , k } \left[\left(\frac{1}{x}\right)^{k+3} e^{\frac{-\theta_{1} \alpha_{1}(j+1)}{x}}+\left(\frac{1}{x}\right)^{k+2} e^{\left.\frac{-\theta_{1} \alpha_{1}(j+1)}{x}\right] .}\right.\right. \\
& =\int_{0}^{\infty}\left\{\sum_{j, k=0}^{\infty} \Xi_{j, k}\left[\left(\frac{1}{x}\right)^{k+3} e^{\frac{-\theta_{1} \alpha_{1}(j+1)}{x}}+\left(\frac{1}{x}\right)^{k+2} e^{\left.\frac{-\theta_{1} \alpha_{1}(j+1)}{x}\right]}\right]\right\} d x \\
& =\int_{0}^{\infty}\left\{\sum_{j, k=0}^{\infty} \sum_{m, p=0}^{\infty} \Xi_{j, k} \Xi_{m, p}\left[\left(\frac{1}{x}\right)^{\frac{-\theta_{2} \alpha_{2} m}{x}}\right]\right] d x \\
& \left.e^{\frac{-\left\{\theta \alpha_{1}(j+1)+\theta_{2} \alpha_{2} m\right\}}{x}}+\left(\frac{1}{x}\right)^{k+p+2} e^{\left.\frac{-\mid\left(\theta_{1} \alpha_{1}(j+1)+\theta_{2} \alpha_{2} m \mid\right.}{x}\right]}\right] d x
\end{aligned}
$$

The stress-strength reliability of KuIL distribution finally takes the following formula

$$
\begin{aligned}
R_{\text {Kull }}= & \sum_{j, k=0}^{\infty} \Xi_{j, k}\left[\frac{\Gamma(k+2)}{\left(\theta_{1} \alpha_{1}(j+1)\right)^{k+2}}+\frac{\Gamma(k+1)}{\left(\theta_{1} \alpha_{1}(j+1)\right)^{k+1}}\right] \\
& -\sum_{j, k=0}^{\infty} \sum_{m, p=0}^{\infty} \Xi_{j, k} \Xi_{m, p}\left[\frac{\Gamma(k+p+2)}{\left[\theta_{1} \alpha_{1}(j+1)+\theta_{2} \alpha_{2} m\right]^{k+2}}+\frac{\Gamma(k+p+1)}{\left[\theta_{1} \alpha_{1}(j+1)+\theta_{2} \alpha_{2} m\right]^{k+1}}\right] .
\end{aligned}
$$

where, $\Xi_{j, k, m, p}=\Xi_{j, k} \Xi_{m, p}$.

Note that $R_{\text {KuIL }}$ does not depend on $\beta$. Additionally, when $\alpha_{1}=\alpha_{2}=\alpha$, then $R_{\text {KuIL }}$ is defined by the following equation:

$$
\begin{aligned}
& S R=\sum_{j, k=0}^{\infty} \Xi_{j, k}\left[\frac{\left\{\theta_{1} \alpha(j+1)+k+1\right\} \Gamma(k+1)}{\left\{\theta_{1} \alpha(j+1)\right\}^{k+2}}\right]- \\
& \sum_{j, k, m, p=0}^{\infty} \Xi_{j, k, m, p}\left[\frac{\left\{k+p-\theta_{1} \alpha(j+1)-\theta_{2} \alpha(m+1)\right\} \Gamma(k+p+1)}{\left[\alpha\left\{\theta_{1}(j+1)+\theta_{2} m\right\}\right]^{k+2}}\right]
\end{aligned}
$$

\subsection{Distribution of Order Statistics}

In this subsection, a closed form expression for the PDF of the $p^{\text {th }}$ order statistics of the 
KuILdistribution will be derived. Let $X_{1}, X_{2}, \ldots, X_{n}$ be a simple random sample fromKuIL distribution with PDF (5), CDF (6) and $X_{1: \mathrm{n}}, X_{2: \mathrm{n}}, \ldots, X_{n: \mathrm{n}}$ denote the order statistics obtained from this sample. By the definition of order statistics distribution:

$$
f_{p: n}(x)=\frac{1}{B(p, n-p+1)}[F(x)]^{p-1}[1-F(x)]^{n-p} f(x) .
$$

Using the binomial series expansion of $[1-F(x)]^{n-p}$ , then, $f_{p: n}(x)$ can be written as

$$
f_{p: n}(x)=\frac{1}{B(p, n-p+1)} \sum_{\varepsilon=0}^{n-p}(-1)^{\varepsilon}\left(\begin{array}{l}
n-p \\
\varepsilon
\end{array}\right)\left[F_{\text {KulL }}(x)\right]^{p+\varepsilon-1} f_{\text {KulL }}(x) .
$$

By substituting from (5) into (16), we obtain

$$
\begin{aligned}
f_{p: n}(x)= & \frac{1}{B(p, n-p+1)} \sum_{\varepsilon=0}^{n-p}(-1)^{\varepsilon}\left(\begin{array}{l}
n-p \\
\varepsilon
\end{array}\right) \frac{\alpha \beta \theta^{2}}{1+\theta}\left(\frac{1+x}{x^{3}}\right)\left(1+\frac{\theta}{(1+\theta) x}\right)^{\alpha-1} \\
& \left(1-\left(1+\frac{\theta}{(1+\theta) x}\right)^{\alpha} e^{\frac{-\theta \alpha}{x}}\right)^{\beta-1}\left[1-\left(1-\left(1+\frac{\theta}{(1+\theta) x}\right)^{\alpha} e^{\frac{-\theta \alpha}{x}}\right)^{\beta}\right]^{p+\varepsilon-1} e^{\frac{-\theta \alpha}{x}} .
\end{aligned}
$$

using

$$
\left[1-\left(1-\left(1+\frac{\theta}{(1+\theta) x}\right)^{\alpha} e^{-\frac{-\theta \alpha}{x}}\right)^{\beta}\right]^{p+\varepsilon-1}=\sum_{\delta=0}^{\infty}(-1)^{\delta}\left(\begin{array}{l}
p+\varepsilon-1 \\
\delta
\end{array}\right)\left(1-\left(1+\frac{\theta}{(1+\theta) x}\right)^{\alpha} e^{\frac{-\theta \alpha}{x}}\right)^{\beta \delta},
$$

therefore

$$
\begin{gathered}
f_{p, n}(x)=\frac{1}{B(p, n-p+1)} \sum_{\delta=0=0}^{\infty} \sum_{k=0}^{n-p}(-1)^{\delta+\delta}\left(\begin{array}{l}
n-p \\
\varepsilon
\end{array}\right)\left(\begin{array}{l}
p+\varepsilon-1 \\
\delta
\end{array}\right) \frac{\alpha \beta \theta^{2}}{1+\theta}\left(\frac{1+x}{x^{3}}\right)\left(1+\frac{\theta}{(1+\theta) x}\right)^{\alpha-1} \\
\left(1-\left(1+\frac{\theta}{(1+\theta) x}\right)^{\alpha} e^{\frac{-\theta \alpha}{x}}\right)^{\beta(\delta+1)-1} e^{\frac{-\theta \alpha}{x}},
\end{gathered}
$$

since

$$
\begin{aligned}
& \left(1-\left(1+\frac{\theta}{(1+\theta) x}\right)^{\alpha} e^{\frac{-\theta \alpha}{x}}\right)^{\beta(\delta+1)-1}=\sum_{\eta=0}^{\infty}(-1)^{\eta}\left(\begin{array}{l}
\beta(\delta+1)-1 \\
\eta
\end{array}\right)\left(1+\frac{\theta}{(1+\theta) x}\right)^{\alpha \eta} e^{\frac{-\theta \alpha \eta}{x}} \\
& \left(1+\frac{\theta}{(1+\theta) x}\right)^{\alpha(\eta+1)-1}=\sum_{\tau=0}^{\infty}\left(\begin{array}{l}
\alpha(\eta+1)-1 \\
\tau
\end{array}\right) \frac{\theta^{\tau}}{(1+\theta)^{\tau} x^{\tau}} .
\end{aligned}
$$

Therefore, the $f_{p: n}(x)$ in equation (17) takes the following formula

$$
f_{p: n}(x)=\frac{1}{B(p, n-p+1)} \sum_{\delta, \eta, p=0}^{\infty} \sum_{\varepsilon=0}^{n-p} \Lambda_{\delta, \eta, \varepsilon}\left(\frac{1+x}{x^{p+3}}\right) \exp \left\{\frac{-\theta \alpha(\eta+1)}{x}\right\}
$$

where,

$$
\Lambda_{\delta, \eta, \varepsilon}=\frac{1}{B(p, n-p+1)} \sum_{\delta=0}^{\infty} \sum_{\eta=0}^{\infty} \sum_{\tau=0}^{\infty} \sum_{\delta=0}^{n-p}(-1)^{\varepsilon+\delta+\eta}\left(\begin{array}{l}
n-p \\
\varepsilon
\end{array}\right)\left(\begin{array}{l}
p+\varepsilon-1 \\
\delta
\end{array}\right)\left(\begin{array}{l}
\beta(\delta+1)-1 \\
\eta
\end{array}\right)\left(\begin{array}{l}
\alpha(\eta+1)-1 \\
\tau
\end{array}\right) \frac{\alpha \beta \theta^{\tau+2}}{(1+\theta)^{\tau+1}}
$$

Specially, the smallest and the greatest order statistics can be computed by taking $p=1$ and $p=$ $n$ in equation (18), respectively.

\section{MAXIMUM LIKELIHOOD ESTIMATION}

Assume $\left\{X_{1}, X_{2}, \ldots, X_{n}\right\}$ be set of independent and identical (iid) random variables of size $n$ from KuIL distribution. Then, the likelihood function based on observed sample $\left\{x_{1}, x_{2}, \ldots, x_{n}\right\}$ is

$$
L(x)=\prod_{j=1}^{n} f_{\text {KulL }}\left(x_{j}\right) \text {. }
$$

The log-likelihood function corresponding to $L(x ; \alpha, \beta, \theta)$ will be

$$
\begin{aligned}
& \begin{array}{l}
\log L(x)=n \ln \left(\frac{\alpha \beta \theta^{2}}{1+\theta}\right)+\sum_{j=1}^{n} \ln \left(\frac{1+x_{j}}{x_{j}^{3}}\right)+(\alpha-1) \sum_{j=1}^{n} \ln \left(1+\frac{\theta}{(1+\theta) x_{j}}\right) \\
+(\beta-1) \sum_{j=1}^{n} \ln \left(1-\left(1+\frac{\theta}{(1+\theta) x_{j}}\right) e^{\frac{-\theta \alpha}{x j}}\right)-\theta \alpha \sum_{j=1}^{n} \frac{1}{x_{j}}
\end{array} \\
& \text { Assuming } Z_{j}=\left(1+\frac{\theta}{(1+\theta) x_{j}}\right) \text {, then } \\
& \log L(x)=n \ln \left(\frac{\alpha \beta \theta^{2}}{1+\theta}\right)+\sum_{j=1}^{n} \ln \left(\frac{1+x_{j}}{x_{j}^{3}}\right)+(\alpha-1) \sum_{j=1}^{n} e^{\frac{-\theta \alpha}{x_{j}}} \ln z_{j}+(\beta-1) \sum_{j=1}^{n} \ln \left(1-z_{j}\right)-\theta \alpha \sum_{j=1}^{n} \frac{1}{x_{j}} .
\end{aligned}
$$

The partial derivatives of $\log L(x)$ with respect to the model parameters $(\alpha, \beta, \theta)$ are

$\frac{\partial \log L(x)}{\partial \alpha}=\frac{n(1+\theta)}{a}+\theta(\beta-1) \sum_{j=1}^{n}\left(\frac{Z_{j}}{x_{j}}\left(1-Z_{j} e^{\frac{-\theta \alpha}{x_{j}}}\right)^{-1} e^{\frac{-\theta \alpha}{x_{j}}}\right)+\sum_{j=1}^{n} \ln Z_{j}-\theta \sum_{j=1}^{n} \frac{1}{x_{j}}$,

$\frac{\partial \log L(x)}{\partial \beta}=\frac{n}{\beta}+\sum_{j=1}^{n} \ln \left(1-Z_{j} e^{\frac{-\theta \alpha}{x_{j}}}\right)$

$\frac{\partial \log L(x)}{\partial \theta}=\frac{n(\theta+2)}{\theta(\theta+1)}+(\alpha-1) \sum_{j=1}^{n}\left(\frac{Z_{j \theta}^{\prime}}{Z_{j}}-\frac{\alpha \ln Z_{j}}{x_{j}}\right) e^{\frac{-\theta \alpha}{x_{j}}}-(\beta-1) \sum_{j=1}^{n} \frac{Z_{j \theta}^{\prime}}{1-z_{j}}-\alpha \sum_{j=1}^{n} \frac{1}{x_{j}}$,

where, $Z_{j \theta}^{\prime}=\frac{\partial Z_{j}}{\partial \theta}=\frac{1}{x_{j}(1+\theta)^{2}}$.

The maximum likelihood estimators of the model parameters $(\alpha, \beta, \theta)$ are determined by solving the nonlinear equations

$\frac{\partial \log L(x)}{\partial \alpha}=0, \frac{\partial \operatorname{og} L(x)}{\partial \beta}=0, \frac{\partial \operatorname{og} L(x)}{\partial \theta}=0$.

These equations cannot be solved in closed form; so software package will be used to solve these equations simultaneously.

To find the interval estimation of the parameters, we have to get the $3 \times 3$ observed information matrix $I(\psi)$ for $(\alpha, \beta, \theta)$. Under the regularity conditions, the known asymptotic properties of the maximum likelihood method ensure that $\sqrt{n}(\widehat{\psi}-\psi)$ $\stackrel{d}{\rightarrow} N_{3}\left(0, I^{-1}(\psi)\right)$ as $n \rightarrow \infty$, where $\stackrel{d}{\rightarrow}$ means the convergence in distribution, with mean $O=(0,0,0)^{T}$ and $3 \times 3$ covariance matrix $I^{-1}(\psi)$ then, the $100(1-q) \%$ confidence intervals for $\alpha, \beta$ and $\theta$ are given, respectively, as follows

$\hat{\alpha} \pm Z q_{/ 2} \sqrt{\operatorname{var}(\hat{\alpha})}$, 
$\hat{\beta} \pm Z q / 2 \sqrt{\operatorname{var}(\hat{\beta})}$, and

$\hat{\theta} \pm Z q / 2 \sqrt{\operatorname{var}(\widehat{\theta})}$, where $Z q / 2$ is the standard normal at $q / 2, q / 2$ is significance level and var (.)'s denote the diagonal elements of $I^{-1}(\psi)$ corresponding to the model parameters.

\section{SIMULATION}

A simulation study for KuIL model is conducted. We have sets of sample of size $n=20,40,100$ from KuIL distribution are created and the parameters have been estimated by the maximum likelihood method. 1000 such iterations are made to compute the bias and mean square error (MSE) of these estimates using the following formula:

$\operatorname{Bias}(\hat{\xi})=\frac{1}{1000} \sum_{i=1}^{1000}(\hat{\xi}-\xi)$,

$\operatorname{MSE}(\hat{\xi})=\frac{1}{1000} \sum_{i=1}^{1000}(\hat{\xi}-\xi)^{2}$,

where, $\hat{\xi}$ is any parameter of a probability distribution.

From Table 1 shows that:

i) While the sample size $n$ increases, the bias decreases. That denotes accuracy of the MLE of the parameters.

ii) While the sample size $n$ increases, the MSE decreases. That denotes consistency (or preciseness) of the MLE of the parameters.

\section{APPLICATIONS}

Kumaraswamy inverse Lindley distribution is fitted comparing with some of the other distributions.

Two groups of real data are applied in this section.

Data set 1: The first data group represents the survival times of patients suffering from Head cancer disease [14]. The patients in this group were treated using radiotherapy (RT): $6.53,7,10.42,14.28,16.1,22.7$, $34,41.55,42,45.28,49.4,53.62,63,64,83,84,91$, $108,112,129,133,139,140,140,146,149,154,157$, $173,176,218,225,241,248,273,277,297,405,417$, 420, 440, 523, 583, 594, 1101, 1146, 1417.

The summarized results of estimated values of the parameters, the Log-likelihood, Akaike information creteria (AIC) [15] and Kolmogorov-Smirnov test statistics are in Table 2.
The PDF of Inverse Rayleigh Distribution [16] is $f(x ; \theta)=\frac{2}{\theta x^{3}} e^{-\frac{1}{\theta x^{2}}} ; x>0, \theta>0$.

Table 1. Bias and MSE of the MLE of parameters for KuIL distribution

\begin{tabular}{|c|c|c|c|c|c|c|}
\hline & \multicolumn{2}{|c|}{$\hat{\theta}=0.1$} & \multicolumn{2}{|c|}{$\hat{\alpha}=0.1$} & \multicolumn{2}{|c|}{$\hat{\beta}=0.1$} \\
\hline $\mathbf{n}$ & BIAS & MSE & BIAS & MSE & BIAS & MSE \\
\hline 20 & -0.1104 & 0.0124 & -0.0957 & 0.0092 & -0.0517 & 0.0030 \\
\hline 40 & -0.1102 & 0.0121 & -0.0955 & 0.0091 & -0.0514 & 0.0027 \\
\hline \multirow[t]{2}{*}{100} & -0.1101 & 0.0120 & -0.0954 & 0.0091 & -0.0511 & 0.0027 \\
\hline & \multicolumn{2}{|c|}{$\hat{\theta}=0.1$} & \multicolumn{2}{|c|}{$\hat{\alpha}=0.1$} & \multicolumn{2}{|c|}{$\hat{\beta}=0.3$} \\
\hline $\mathrm{n}$ & BIAS & MSE & BIAS & MSE & BIAS & MSE \\
\hline 20 & -0.1099 & 0.0123 & -0.0963 & 0.0093 & -0.2506 & 0.0630 \\
\hline 40 & -0.1099 & 0.0121 & -0.0962 & 0.0093 & -0.2504 & 0.0629 \\
\hline \multirow[t]{2}{*}{100} & -0.1097 & 0.0121 & -0.0960 & 0.0092 & -0.2502 & 0.0628 \\
\hline & \multicolumn{2}{|c|}{$\hat{\theta}=0.1$} & \multicolumn{2}{|c|}{$\hat{\alpha}=0.2$} & \multicolumn{2}{|c|}{$\hat{\beta}=0.3$} \\
\hline $\mathrm{n}$ & BIAS & MSE & BIAS & MSE & BIAS & MSE \\
\hline 20 & -0.1099 & 0.0123 & -0.1963 & 0.0385 & -0.2525 & 0.0638 \\
\hline 40 & -0.1097 & 0.0121 & -0.1960 & 0.0384 & -0.2510 & 0.0631 \\
\hline \multirow[t]{2}{*}{100} & -0.1097 & 0.0121 & -0.1960 & 0.0384 & -0.2509 & 0.0630 \\
\hline & \multicolumn{2}{|c|}{$\hat{\theta}=0.2$} & \multicolumn{2}{|c|}{$\hat{\alpha}=0.2$} & \multicolumn{2}{|c|}{$\hat{\beta}=0.3$} \\
\hline $\mathbf{n}$ & BIAS & MSE & BIAS & MSE & BIAS & MSE \\
\hline 20 & -0.2099 & 0.0443 & -0.1961 & 0.0384 & -0.2512 & 0.0632 \\
\hline 40 & -0.2099 & 0.0441 & -0.1959 & 0.0384 & -0.2509 & 0.0630 \\
\hline \multirow[t]{2}{*}{100} & -0.2098 & 0.0440 & -0.1959 & 0.0384 & -0.2508 & 0.0630 \\
\hline & \multicolumn{2}{|c|}{$\hat{\theta}=0.2$} & \multicolumn{2}{|c|}{$\hat{\alpha}=0.3$} & \multicolumn{2}{|c|}{$\hat{\beta}=0.2$} \\
\hline $\mathrm{n}$ & BIAS & MSE & BIAS & MSE & BIAS & MSE \\
\hline 20 & -0.2099 & 0.0443 & -0.2962 & 0.0877 & -0.1513 & 0.0230 \\
\hline 40 & -0.2099 & 0.0441 & -0.2960 & 0.0876 & -0.1510 & 0.0229 \\
\hline \multirow[t]{2}{*}{100} & -0.2098 & 0.0441 & -0.2959 & 0.0876 & -0.1508 & 0.0229 \\
\hline & \multicolumn{2}{|c|}{$\hat{\theta}=0.5$} & \multicolumn{2}{|c|}{$\hat{\alpha}=0.1$} & \multicolumn{2}{|c|}{$\hat{\beta}=0.1$} \\
\hline $\mathrm{n}$ & BIAS & MSE & BIAS & MSE & BIAS & MSE \\
\hline 20 & -0.5100 & 0.2601 & -0.0959 & 0.0092 & -0.0517 & 0.0028 \\
\hline 40 & -0.5100 & 0.2601 & -0.0958 & 0.0092 & -0.0517 & 0.0027 \\
\hline 100 & -0.5100 & 0.2600 & -0.0956 & 0.0092 & -0.0514 & 0.0027 \\
\hline & $\hat{\theta}=$ & & $\hat{\alpha}=$ & .5 & $\hat{\beta}=$ & \\
\hline $\mathrm{n}$ & BIAS & MSE & BIAS & MSE & BIAS & MSE \\
\hline 20 & -0.1109 & 0.0123 & -0.4953 & 0.2453 & -0.0508 & 0.0030 \\
\hline 40 & -0.1107 & 0.0123 & -0.4952 & 0.2452 & -0.0500 & 0.0029 \\
\hline 100 & -0.1107 & 0.0123 & -0.4949 & 0.2449 & -0.0499 & 0.0027 \\
\hline & & & $\hat{\alpha}=$ & 0.1 & & \\
\hline $\mathrm{n}$ & BIAS & MSE & BIAS & MSE & BIAS & MSE \\
\hline 20 & -0.1102 & 0.0122 & -0.0962 & 0.0093 & -0.4510 & 0.2035 \\
\hline 40 & -0.1100 & 0.0121 & -0.0959 & 0.0092 & -0.4502 & 0.2031 \\
\hline 100 & -0.1100 & 0.0121 & -0.0959 & 0.0092 & -0.4498 & 0.2025 \\
\hline & & & $\hat{\alpha}=$ & 0.5 & $\hat{\beta}=$ & \\
\hline $\mathbf{n}$ & BIAS & MSE & BIAS & MSE & BIAS & MSE \\
\hline 20 & -0.5099 & 0.2601 & -0.4960 & 0.2460 & -0.4514 & 0.2038 \\
\hline 40 & -0.5099 & 0.2600 & -0.4959 & 0.2459 & -0.4513 & 0.2038 \\
\hline 100 & -0.5099 & 0.2600 & -0.4952 & 0.2453 & -0.4511 & 0.2035 \\
\hline
\end{tabular}

Table 2. The results of fitting different distributions to the 1st data.

\begin{tabular}{|l|l|c|c|}
\hline Distribution & Estimate of the parameter & $\begin{array}{c}\text { Log- } \\
\text { likelihood }\end{array}$ & AIC \\
\hline Ku ILD & $\alpha^{\wedge}=5.66, \beta^{\wedge}=0.70, \theta^{\wedge}=7.97$ & -319.26 & 644.52 \\
\hline ILD & $\theta^{\wedge}=55.45$ & -340.75 & 683.50 \\
\hline IRD & $\theta^{\wedge}=27,228$ & -419.06 & 840.13 \\
\hline
\end{tabular}


The histogram shows that the data set is positively skewed. Kumar et al. [17] fitted this data to the inverse Lindley distribution. We have fitted this data with the Kumaraswamy inverse Lindley distribution (KuILD) compared with the inverse Rayleigh distribution (IRD) and inverse Lindly distribution (ILD).

The histogram, fitted PDF, and estimated CDF of the models to this data have been shown in Figure 4a and 4b.

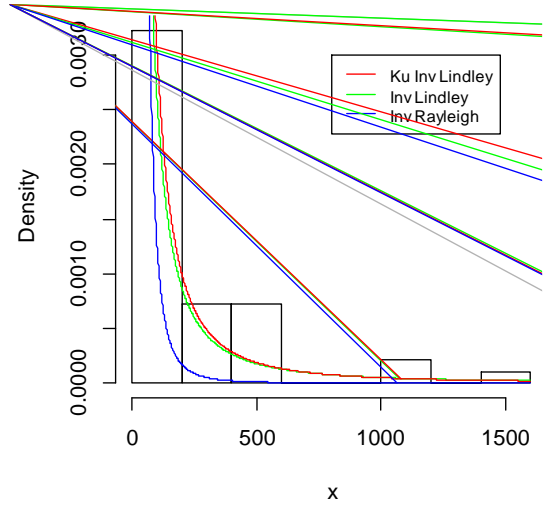

(a)

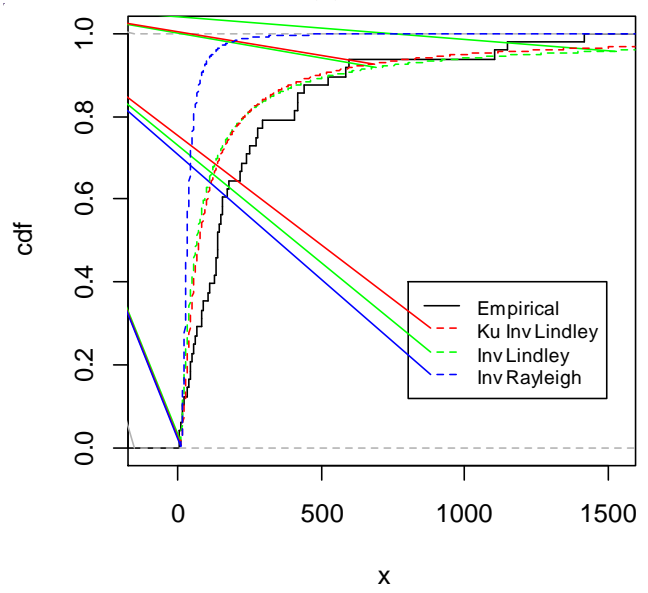

(b)

Figure 4. a) Plots of histogram and fitted PDF with compared models for $1^{\text {st }}$ data, b) Plots of estimated CDF with compared models for $1^{\text {st }}$ data.

Data set 2: The second data set shows the survival times of patients suffering from Neck cancer disease [14]. The patients in this group were treated using a combined radiotherapy and chemotherapy $(\mathrm{CT}+\mathrm{RT})$ : $12.2,23.56,23.74,25.78,31.98,37,41.35,47.38$, $55.46,58.36,63.47,68.46,78.26,74.47,81.43,84$, $92,94,110,112,119,127,130,133,140,146,155$, $159,173,179,194,195,209,249,281,319,339,432$, 469, 519, 633, 725, 817, 1776.

Kumar et al. [17] fitted this data to the inverse Lindley distribution. We have fitted this data with KuILD compared with ILD and IRD. The summarized results of the estimated values of the parameters (Log- likelihood, AIC and Kolmogorov-Smirnov test statistics) are in Table 3. The histogram, fitted PDF, and estimated CDF of the KuIL curve to data have been shown in Figure $5 \mathrm{a}$ and $5 \mathrm{~b}$.

The selection criterion is that the lowest Loglikelihood and AIC correspond to the best model fitted. The MLEs, AIC are shown in Table 3. From the Table, we observe that the Kumaraswamy inverse Lindley distribution shows the smaller Log-likelihood and AIC than other competing distributions. Thus, the KuIL distribution fits well with the second real data set.

We observe from plots of probability density and fitted cumulative distributions of KuIL are shown in Figure $4 \mathrm{a}$ and $4 \mathrm{~b}$ for the $1^{\text {st }}$ data and figure $5 \mathrm{a}$ and $5 \mathrm{~b}$ for the $2^{\text {nd }}$ data. Figures also indicate that the KuIL distribution is a well fitted model for the real data sets.

Table 3. The results of fitting different distributions to the $2^{\text {nd }}$ data.

\begin{tabular}{|l|l|l|l|}
\hline Distribution & Parameter estimates & $\begin{array}{l}\text { Log- } \\
\text { likelihood }\end{array}$ & AIC \\
\hline Ku ILD & $\alpha^{\wedge}=7.97, \beta^{\wedge}=1.17, \theta^{\wedge}=11.54$ & -279.32 & 564.64 \\
\hline ILD & $\theta^{\wedge}=77.67$ & -344.10 & 690.21 \\
\hline IRD & $\theta^{\wedge}=50.474$ & -480.35 & 962.71 \\
\hline
\end{tabular}

\section{CONCLUSION}

We present a new three-parameter distribution KuILwhich generalizes IL distribution. Some of their structural properties are obtained as shapes, quantiles, moments, incomplete moments, and moment generating functions. Additionally, mean, median, stress strength reliability, and order statistics are deduced. The new distribution is explored with the estimation of the parameters via the maximum likelihood method. The KuIL model supplies a consistently better fit than the other models selected from the literature. Finally, the results provide that the KuIL has many applications in reliability, medicine, engineering, and survival analysis. 


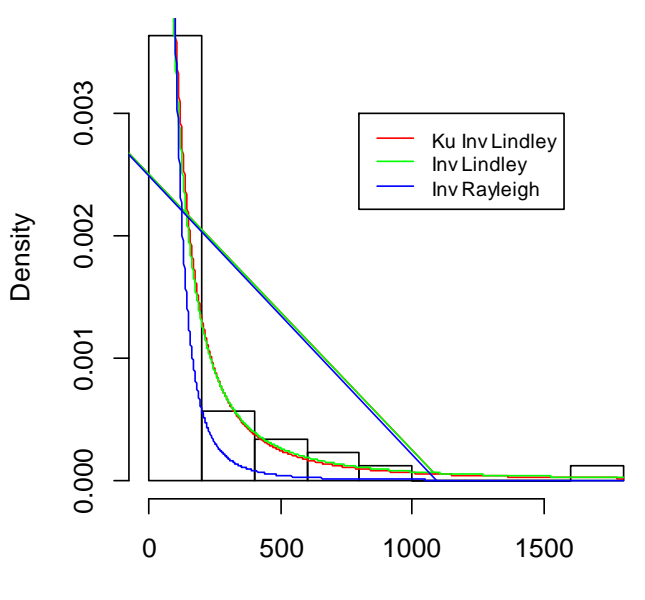

(a)

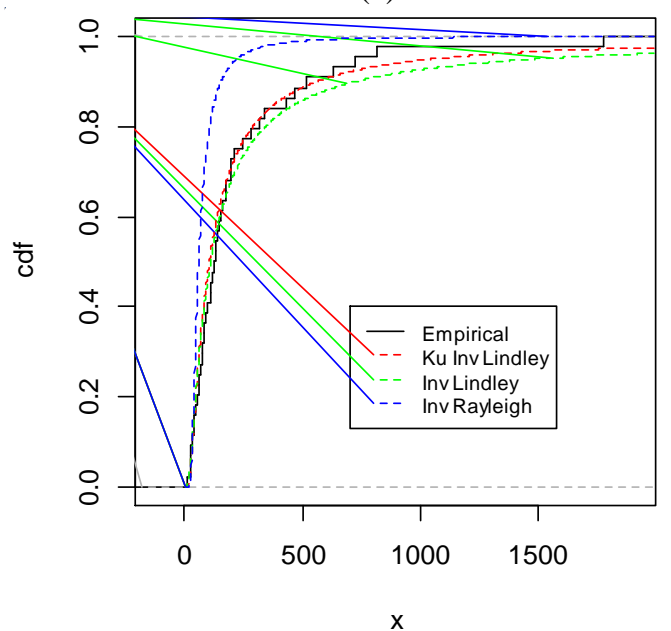

(b)

Figure 5. a) Plots of histogram and fitted PDF with compared models for $2^{\text {nd }}$ data, b) Plots of estimated CDF with compared models for $2^{\text {nd }}$ data.

\section{CONFLICTS OF INTEREST}

The authors reported no potential conflict of interest.

\section{REFERENCES}

[1] Merovci, F., and Sharma, V. K. "The beta-Lindley distribution: properties and applications". Journal of Applied Mathematics,5(4), 24-47. 2014

[2] Alkarni, S. H. "Extended inverse Lindley distribution: properties and application". Springer Plus, vol. 4, no. 1, pp. 690, 2015.

[3] Sharma, V. K., Singh, S. K., Singh, U., and Merovci, F. "The generalized inverse Lindley distribution: A new inverse statistical model for the study of upside-down bathtub data". Communications in Statistics-Theory and Methods, vol. 45, no. 19, pp. 5709-5729, 2016.

[4] Sharma, V. K., and Khandelwal, P. "On the extension of inverse Lindley distribution". Journal of Data Science, vol. 15, no. 2, pp. 205-220, 2017.

[5] Kumaraswamy, P. "A generalized probability density function for double-bounded random processes". Journal of Hydrology, vol. 46, no. 1, pp. 79-88, 1980.

[6] Nadarajah, S., Cordeiro, G. M., and Ortega, E. M. "General results for the Kumaraswamy-G distribution". Journal of Statistical Computation and Simulation, vol. 82, no. 7, pp. 951-979, 2012.

[7] Paranaiba, P. F., Ortega, E. M., Cordeiro, G. M., and de Pascoa, M. A. "The Kumaraswamy Burr XII distribution: theory and practice". Journal of Statistical Computation and Simulation, vol. 83, no. 11, pp. 2117-2143, 2013.

[8] Gomes, A. E., da-Silva, C. Q., Cordeiro, G. M., and Ortega, E. M. "A new lifetime model: the Kumaraswamy generalized Rayleigh distribution". Journal of Statistical Computation and Simulation, vol. 84, no. 2, pp. 290-309, 2014.

[9] Cordeiro, G. M., Ortega, E. M., and Nadarajah, S. "The Kumaraswamy Weibull distribution with application to failure data". Journal of the Franklin Institute, vol. 347, no. 8, pp. 1399-1429, 2010

[10] Cordeiro, G. M., Saboor, A., Khan, M. N., Ozel, G., and Pascoa, M. A. "The Kumaraswamy Exponential-Weibull Distribution: Theory and Applications". Hacettepe journal of mathematics and statistics, vol. 45, no. 4, pp. 1203-1229, 2016.

[11] Al-Babtain, A., Fattah, A. A., Ahmed, A. H. N., and Merovci, F. "The Kumaraswamy-transmuted exponentiated modified Weibull distribution". Communications in StatisticsSimulation and Computation, vol. 46, no. 5, pp. 38123832, 2017.

[12] Gupta, P. L. and Gupta, R. C. "On the moments of residual life in reliability and some characterization results". Communications in Statistics-Theory and Methods, vol. 12, no. 4, pp. 449-461, 1983.

[13] Rényi, A. "On measures of entropy and information", Proceedings of the 4th Berkeley Symposium on Mathematical Statistics and 
Probability, University of California Press, Berkeley, vol. 547-561, 1961.

[14] Efron, B. "Logistic regression, survival analysis, and the kaplan-meier curve", Journal of the American Statistical Association, vol. 83, pp. 414-425, 1988.

[15] Akaike, H. "A new look at the statistical model identification". IEEE Transactions on Automatic Control, vol. 19, no. 6, pp. 716-723, 1974.

[16] Voda, V. G. "On the inverse Rayleigh distributed random variable". Reports of Statistical Application Research, vol. 19, pp. 13-21. 1972.

[17] Kumar, P., Sharma, R., Ray, S., Mehariya, S., Patel, S. K., Lee, J. K., and Kalia, V. C. "Dark fermentative bioconversion of glycerol to hydrogen by Bacillus thuringiensis". Bioresource technology, vol. 182, pp. 383-388, 2015. 